\section{THE DENVER MEETING OF THE} AMERICAN ASSOCIATION.

THE American Association held its fiftieth annual meeting at Denver, Colorado, during the week beginning August 24, under the presidency of Prof. Charles S. Minot, of Harvard University. This is the first time that the Association has met west of the banks of the Mississippi River, and the meeting consequently marks a somewhat important epoch in the development of science in America. The central and western States have occupied somewhat the same position towards the Atlantic seaboard as this part of the country held in relation to Europe until about twenty-five years ago. Until the development of the eastern universities, the scientific men of the United States were largely trained abroad and looked chiefly to Great Britain and the Continent for their scientific models. Up to the present time the central and western States-engaged in subduing Nature on a scale hitherto unattempted-have depended on the Atlantic States for their education, their science and their literature. The development of the universities in the central and western States during the past ten years has, however, been remarkable. Of the forty universities in the world having more than 2000 students, seven-Michigan, Chicago, North-Western, Wisconsin, Minnesota, Illinois and California-are situated in this region; and these institutions are not mere schools, but universities and centres for the advancement of science, rivalling Leipzig or Cambridge in their standards and in their productiveness. The time has obviously come when men of science in the west can meet on equal terms their colleagues in the east, and this event was signalised by the meeting of the Association at Denver, midway between the Atlantic and Pacific coasts. The meeting, though not so largely attended as is usual further to the east-the members from either the Atlantic or Pacific coasts had 2000 miles to travel-was successful both on its social and scientific sides. Hospitality is the virtue of a new country, and the people of Denver were prepared to entertain the Association by social functions and excursions in a way that is not usual in the United States.

Before the ten sections into which the Association is divided some two hundred and twenty papers were presented, and while perhaps none of them was of such importance as to deserve special notice, they represented on the whole a high level of scientific work. The address of the retiring president, Prof. R. S. Woodward, of Columbia University, appears in the present issue of Nature. Public addresses on topics suited to the place of meeting were made by Prof. C. R. Van Hise, who discussed the nature of ore deposits, and by Mr. Gifford Pinchot, chief of the Bureau of Forestry, who considered questions of irrigation and forestration.

Owing to a change in procedure by which the chairmen of sections give their addresses when retiring from office, there were this year only five such addresses. Before the section of chemistry, Prof. J. H. Long, of NorthWestern University, took as the subject of his address the development of the teaching of chemistry in the United States; before the section of mechanical science and engineering, Mr. John A. Brashear, acting Chancellor of the Western University of Pennsylvania, described the plans, drawn up at Mr. Carnegie's request, for a great technical college at Pittsburg which would call for an endowment of from $10,000,200$ to $20,000,000$ dollars ; before the section of zoology, Prof. Charles B. Davenport, of the University of Chicago, discussed the quantitative study of variation-a subject to which he has devoted special attention, being associated with Profs. Pearson and Weldon in the newly established journal Biometrika; before the section of anthropology, Mr. Amos W. Butler, of the Indiana State Board of Charities, described the methods used under his direction for the care of the feeble minded in the State of Indiana, with scientific deductions on heredity and the like ; before the section of social and economic science, Prof. C. M. Woodward, of Washington University, St. Louis, and a leader in the introduction of manual training into the schools of the United States, discussed what he called "The change of front in education." A new section of the Association, devoted to physiology and experimental medicine, was organised and will hold its first meeting for the reading of papers next year.

The business transacted at the meeting was of unusual importance. The first report was made in regard to the plan of sending the weekly journal, Science, free of charge to all members of the Association. It is apparently working well, for this and the efficiency of the present permanent secretary, Dr. L. O. Howard, has resulted in an addition of about I 500 permanent new members, chiefly scientific men, in the course of the year. The American Association is becoming a centre for national scientific societies, and hereafter the societies devoted to the special sciences will be represented on the council of the Association. Efforts have recently been made to secure for America a convocation week for the meetings of scientific and learned societies, and the leading universities have agreed to set aside for this purpose the week in which January I falls. The American Association will hold a meeting in mid-winter at Washington at the beginning of the year 1903 , when there will be a congress of at least twenty scientific societies. The next meeting of the Association will, however, be at Pittsburg at the beginning of next July. It will be presided over by the eminent astronomer, Dr. Asaph Hall.

\section{Address by Prof. R. S. Woodward, President of} THE ASSOCIATION.

\section{The Progress of Science.}

A Constitutional provision of our Association stipulates that "It shall be the duty of the President to give an address at a General Session of the Association at the meet. ing following that over which he presided." Happily for those of us who must in turn fulfil this duty, the scientific foresight of our predecessors set no metes and bounds with respect to the subject-matter or the mode of treatment of the theme that might be chosen for such an address. So far, therefore, as constitutional requirements are concerned, a retiring president finds himself clothed for the time being with a degree of liberty which might be regarded as dangerous were it not for an unwritten rule that one may not hope to enjoy such liberty more than once. But time and place, nevertheless, as well as the painful personal limitations of any specialist, impose some rather formidable restrictions. One may not tax lightly, even, in a summer evening, the patience of his audience for more than an academic hour, the length of which in most cases is less than sixty minutes. One must confine himself to generalities, which, though scientifically hazardous, serve as a basis for semi-popular thought ; and one must exclude technical details, which, though scientifically essential, tend only to obscure semi-popular presentation. Courtesy, also, to those who are at once our hosts and our guests requires that, so far as possible, one should substitute the vernacular for the " jargon of science," and draw his figures of speech chiefly from the broad domain of every-day life rather than from the special, though rapidly widening, fields of scientific activity.

Between this nominally unlimited freedom on the one hand, and these actually narrow restrictions on the other, I have chosen to invite your attention for the hour to a summary view of the salient features of scientific progress, with special reference to its effects on the masses, rather than on the individuals, of mankind. We all know, at least in a general way, what such progress is. We are assured almost daily by the public Press and by popular consent that the present is not only an age of scientific progress but that it is preeminently the age of scientific progress. And with respect to the future of scientific achievement, the consensus of expert opinion is cheerfully hopeful and the consensus of public opinion is extremely optimistic. Indeed, to borrow the language sometimes used by the rulers of nations,

NO. I 664, VOL. 64] 
it may be said that the realm of science is now at peace with all foreign parts of the world and in a state of the happiest domestic prosperity.

But times have not been always thus pleasant and promising for science. As we look backward over the history of scientific progress it is seen that our realm has been taxed often to the utmost in defence of its autonomy, and that the present state of domestic felicity, bordering on tranquillity. has been preceded often by states of domestic discord bordering on dissolution. And, as we look forward into the new century before us, we may well inquire whether science has vanquished its foreign enemies and settled its domestic disputes for good and all, or whether future conquests can be made only by a similarly wasteful outlay of energy to that which has accompanied the advances of the past. Especially may we fitly inquire on an occasion like the present what are the types of mind and the methods of procedure which make for the progress, and what are the types of mind and the methods of procedure which make for the regress, of science. And I venture to think that we may inquire also with profit, in some prominent instances, under what circumstances in the past science has waxed or waned, as the case may be, in its slow rise from the myths and mysticism of earlier eras to the law and order of the present day. For it is a maxim of common parlance, too well justified, alas! by experience, that history repeats itself; or, to state the fact less gently, that the blunders and errors of one age are repeated with little variation in the succeeding age. This maxim is strikingly illustrated by the history of science, and it has been especially deeply impressed upon us-burnt in, one might say-by the scientific events of our own times. Have we not learned, however, some lasting lessons in the hard school of experience, and may we not transmit to our successors along with the established facts and principles of science the almost equally well established ways and means for the advancement of science? Will it be possible for society to repeat in the twentieth century the appalling intellectual blunders of the nineteenth century, or have we entered on a new era in which, whatever other obstacles are pending, we may expect man to stand notably less in his own light as regards science than ever before? To a consideration of these and allied questions I beg your indulgence, even though I may pass over ground well known to most of you, and encroach, perhaps, here and there, on prominences in fields controversial; for it is only by discussion and rediscussion of such questions that we come at last, even among ourselves in scientific societies, to the unity of opinion and the unity of purpose which lead from ideas to their fruitful applications.

From the earliest historic times certainly, if not from the dawn of primitive humanity, down to the present day, the problem of the universe has been the most attractive and the most illusive subject of the attention of thinking men. All systems of philosophy, religion and science are alike in having the solution of this problem for their ultimate object. Many such systems and sub-systems have arisen, flourished and vanished, only to be succeeded by others in the seemingly Sisyphean task. Gradually, however, in the lapse of ages there have accumulated some elements of knowledge which give inklings of partial solutions; though it would appear that the best current opinion of philosophy, religion and science would again agree in the conclusion that we are yet immeasurably distant from a complete solution. Almost equally attractive and interesting, and far more instructive, as it appears to me, in our own time is the contemplation of the ways in which man has attacked this perennial riddle. It is, indeed, coming to be more and more important for science to know how primitive, barbarous, and civilised man has visualised the conditions of, and reached his conclusions with respect to, this problem of the centuries ; for it is only by means of a lively knowledge of the baseless hypotheses and the fruitless methods of our predecessors that we can hope to prevent history from repeating itself unfavourably.

Looking back over the interval of two to three thousand years that connects us by more or less authentic records with our distinguished ancestors, we are at once struck by the admirable confidence they had acquired in their ability to solve this grand problem. Not less admirable, also, for their ingenuity and for the earnestness with which they were advanced, are the hypotheses and the arguments by which men satisfied themselves of the security of their tenets and theories. Roughly speaking, it would appear that the science of the universe received its initial impulse from earliest man in the hypothesis that the world is composed of two parts, the first and most important part being, in fact, if not always so held ostensibly, himself, and the other part being the aggregate of whatever else was left over. Though dimly perceived and of little account in its effects, this is, apparently, the working hypothesis of many men in the civilised society of to-day. But the magnitude of the latter part and its inexorable relations to man seem to have led him speedily to the adoption of a second hypothesis, namely, that the latter part, or world external to himself, is also the abode of sentient beings, some of a lower and some of a higher order than man, their rôle tending on the whole to make his sojourn on this planet tolerable and his exit from it creditable, while yet wielding at times a more or less despotic influence over him.

How the details of these hypotheses have been worked out is a matter of something like history for a few nationalities, and is a matter absorbing the attention of anthropologists, archæologists, and ethnologists as it concerns races in general. Without going far afield in these profoundly interesting and instructive details, it may suffice for the present purposes to cite two facts which seem to furnish the key to a substantially correct interpretation of subsequent developments.

The first of these is that the early dualistic and antithetical visualisation of the problem in question has persisted with wonderful tenacity down to the present day. The accessible and familiar was set over against the inaccessible and unfamiliar ; or, what we now call the natural, though intimately related to, was more or less opposed to the supernatural, the latter being, in fact, under the uncertain sway of, and the former subject to the arbitrary jurisdiction of, good and evil spirits.

The second fact is that man thus early devised for the investigation of this problem three distinct methods, which have likewise persisted with equal tenacity, though with varying fortunes, down to the present day. The first of these is what is known as the $a$ priori method. It reasons from subjective postulates to objective results. It requires, in its purity, neither observation nor experiment on the external world. It often goes so far, indeed, as to adopt conclusions and leave the assignment of the reasons for them to a subsequent study. The second is known as the historico-critical method. It depends, in its purity, on tradition, history, direct human testimony and verbal congruity. It does not require an appeal to Nature except as manifested in man. It limits observation and experiment to human affairs. The third is the method of science. It begins, in its elements, with observation and experiment. Its earlier applications were limited mostly to material things. In its subsequent expansion it has gained a footing in nearly every field of thought. Its prime characteristic is the insistence on objective verification of its results.

All of these methods have been used more or less by all thinking men. But for the purposes of ready classification it may be said that the first has been used chiefly by dogmatists, including especially the founders and advocates of all fixed creeds from the atheistic and pantheistic to the theistic and humanistic; the second has been used chiefly by humanists, including historians, publicists, jurists and men of letters ; and the third has been used chiefly by men of science, including astronomers, mathematicians, physicists, naturalists and, more recently, the group of investigators falling under the comprehensive head of anthropologists. The first and the third methods are frequently found to be mutually antithetical, if not mutually exclusive. The second occupies middle ground. Together they are here set down in the order of their apparent early development and in the order of their popularly esteemed importance during all historic time previous to, if not including, this first year of the twentieth century.

No summary view of the progress of science, it seems to me, can be made intelligible except by a clear realisation of these two facts, which may be briefly referred to as man's conception of the universe and his means of investigating it. What, then, in the light of these facts, has been the sequel? The full answer to this question is an old and a long story, now a matter of minute and exhaustive history as regards the past twenty centuries. I have no desire to recall the dramatic events involved in the rise of science from the Alexandrian epoch to the present day. All these events are trite enough to men of science. A mere reference to them is a sufficient suggestion of the existence of a family skeleton. But, setting aside the human element as much as possible, it may not be out of place or time to state what general conclusions appear to stand out clearly in 
that sequel. These are our tangible heritage, and upon them we should fix our attention.

In the first place, the progress of science has been steadily opposed to, and as steadily opposed by, the adherents of man's primitive concepts of the universe. The domain of the natural has constantly widened and the domain of the supernatural has constantly narrowed. So far, at any rate, as evil spirits are concerned, they have been completely cast out from the realm of science. The arch fiend and the lesser princes of darkness are no longer useful even as an hypothesis. We have reachedif I may again use the cautious language of diplomacy-a satis. factory modus vivendi if we have not attained permanent peace in all our foreign relations. Enlightened man has come to see that his highest duty is to cooperate with Nature, that he may expect to get on very well if he heeds her advice, and that he may expect to fare very ill if he disregards it.

Secondly, it appears to have been demonstrated that neither the a priori method of the dogmatists nor the historico-critical method of the humanists is alone adequate for the attainment of definite knowledge of either the internal or the external world, or of their relations to one another. In fact, it has been shown over and over again that man cannot trust his unaided senses even in the investigation of the simplest and most obvious material phenomena. There is an ever present need of a correction for personal equation. Left to himself, the a priori reasoner weaves from the tangled skein of thought webs so well tied by logical knots that there is no escape for the imprisoned mind except by the rude process applied to cobwebs. And in the serenity of his repose behind the fortress of "liberal culture" the reactionary humanist will prepare apologies for errors and patch up compromises between traditional beliefs and sound learning with such consummate literary skill that even "the good demon of doubt " is almost persuaded that if knowledge did not come to an end long ago it will soon reach its limit. In short, we have learned, or ought to have learned, from ample experience, that in the search for definite, verifiable knowledge we should beware of the investigator whose equipment consists of a bundle of traditions and dogmas along with formal logic and a facile pen; for we may be sure that he will be more deeply concerned with the question of the safety than with the question of the soundness of scientific doctrines.

Thirdly, it has been demonstrated equally clearly and far more cogently that the sort of knowledge we call scientific, knowledge which has in it the characteristics of immanence and permanence, is founded on observation and experiment. The rise and growth of every science illustrate this fact. Even pure mathematics, commonly held to be the a priori science par excellence, and sometimes called "the science of necessary conclusions," is no exception to the rule. Those who would found mathematics on a higher plane have apparently forgotten to consider the contents of the mathematician's waste-basket. The slow and painful steps by which astronomy has grown out of astrology and chemistry out of alchemy; and the faltering, tedious, and generally hotly contested advances of geology and biology, have been made secure only by the remorseless disregard which observational and experimental evidence has shown for the foregone conclusions of the dogmatists and the literary opinions of the humanists. Thus it has been proved by the rough logic of facts and events that the rude processes of "trial and error," processes which many philosophers and some men of science still affect to despise, are the most effective means yet devised by man for the discovery of truth and for the eradication of error.

These facts are so well known to most of you, so much a matter of ingrained experience, that the categorical mention of them here may seem like a rehearsal of truisms. But it is one of the paradoxes of human development that errors which have been completely dislodged from the minds of the few may still linger persistently in the minds of the many, and that the misleading hypotheses and the dead theories of one age may be resuscitated again and again in succeeding ages. Thus, to cite one of the simplest examples, it doubtless appeared clear to the Alexandrian school that the flat, four-cornered earth of contemporary myths would speedily give way to the revelations of geometry and astronomy. How inadequate such revelations proved to be at that time is one of the most startling disclosures in all history. The "Divine School of Alexandria" passed into oblivion. The myth of a flat and four-cornered earth was crystallised into a dogma strong enough to bear the burden of men's souls by Cosmas Indicopleustes in the sixth century; it was supported with still more invincible arguments by Martin Luther in the sixteenth century; and it was revived and maintained with not less truly admirable logic, as such, by John Hampden and John Jasper in the last decades of the nineteenth century. To cite examples from contemporary history showing how difficult it is for the human mind to get above its primitive conceptions, one needs only to refer to the daily Press. During the past two months, in fact, the newspapers have related how men, women and children, many of them suffering from loathsome if not contagious diseases, have visited a veritable middle-age shrine in the city of New York, strong in the hoary superstition that kissing an alleged relic of St. Anne would remove their afflictions. During the same interval a railway circular has been distributed explaining how tourists may witness the Moki snake-dance, that weird ceremony by which the Pueblo Indian seeks to secure rain in his desert; and a similar public, and officially approved, ceremony has been observed in the heat-stricken State of Missouri.

Such epochs and episodes of regression as these must be taken into account in making up an estimate of scientific progress. They show us that the slow movement upward in the evolution of man which gives an algebraic sum of a few steps forward per century is not inconsistent with many steps backward. Or, to state the case in another way, the rate of scientific advance is to be measured not so much by the positions gained and held by individuals, as by the positions attained and realised by the masses of our race. The average position of civilised man now is probably below the mean of the positions attained by the naturalist Huxley and the statesman Gladstone, or below the mean of the positions attained by the physicist von Helmholtz and His Holiness the Pope. When measured in this manner, the rate of progress in the past twenty centuries is not altogether flattering or encouraging to us, especially in view of the possibility that some of the recently developed sciences may suffer relapses similar to those which so long eclipsed geography and astronomy.

It must be confessed, therefore, when we look backward over the events of the past two thousand years, and when we consider the scientific contents of the mind of the average denizen of this planet, that it is not wholly rational to entertain millennial anticipations of progress in the immediate future. The fact that some of the prime discoveries of science have so recently appeared to many earnest thinkers to threaten the very foundations of society is one which should not be overlooked in these confident times of prosperity. And the equally important fact that entire innocence with respect to the elements of science and dense ignorance with respect to its methods have not been hitherto incompatible with justly esteemed eminence in the divine, the statesman, the jurist, and the man of letters, is one which should be reckoned with in making up any forecast. It may be seriously doubted, indeed, whether the progress of the individual is not essentially limited by the progress of the race.

But this obverse and darker side of the picture which confronts us from the past has its reverse and brighter side; and $I$ am constrained to believe that the present status of science and the general enlightenment of humanity justify ardent hopefulness if not sanguine optimism with respect to the future of scientific achievement. The reasons for this hopefulness are numerous; some of them arising out of the commercial and political con. ditions of the world, and others arising out of the conditions of science itself.

Perhaps the most important of all these reasons is found in the general enlargement of ideas which has come, and is coming, with the extension of trade and commerce to the uttermost parts of the earth. We are no longer citizens of this or that country, simply. Whether we wish it or not we are citizens of the world, with increased opportunities and with increased duties. We may not approve-few men of science would approve, I think-that sort of "expansion" which works "benevolent assimilation" of inferior races by means of a bible in one hand and a gun in the other; but nothing can help so much, it seems to me, to remove the stumbling blocks in the way of the progress of science as actual contact with the manners, the customs, the relations, and the resulting questions for thought, now thrust upon all civilised nations by the events of the day. That sort of competition which is the life of trade, that sort of rivalry which is the stimulus to national effort, and that sort of cooperation which is essential for mutual protection, all make for the cosmopolitan dissemination of scientific truth and for the appreciation of scientific investigation. I would not 
disparage the elevated aspirations and the noble efforts of the evangelists and the humanists who seek to raise the lower to the plane of the higher elements of our race; but it is now plain as a matter of fact, however repulsive it may seem to some of our inherited opinions, that the railway, the steamship, the telegraph, and the daily Press will do more to illumine the dark places of the earth than all the apostles of creeds and all the messengers of the gospel of "sweetness and light."

A question of profound significance growing out of the extension of commercial relations in our time is what may be called the question of international health. An outbreak of cholera in Hamburg, the prevalence of yellow fever in Havana, or an epidemic of bubonic plague in India is no longer a matter of local import, as nations with which we are well acquainted have learned recently in an expensive manner. The management of this great international question calls for the application of the most advanced scientific knowledge and for the most intricate scientific investigation. Large sums of money must be devoted to this work, and many heroic lives will be lost, doubtless, in its execution; but it is now evident, as a mere matter of international political economy, that the cost of sound sanitation will be trifling in comparison with the cost of no sanitation; while further careful study of the natural history of diseases promises practical immunity from many of them at no distant day. International associations of all kinds must aid greatly also in the promotion of progress. Many such organisations have, indeed, already undertaken scientific projects with the highest success. Comparison and criticism of methods and results not only lead rapidly and effectively to improvements and advances, but they lead aiso to a whole-hearted recognition of good work which puts the fraternalism of men of science on a plane far above the level of the amenities of merely diplomatic life.

When we turn to the general status of science itself, there is seen to be equal justification for hopefulness founded on an abundance of favourable conditions. The methods of science may be said to have gained a footing of respectability in almost every department of thought, where, a half century ago, or even twenty years ago, their entry was either barred out or stoutly opposed. The "Conflict between Religion and Science"more precisely called the conflict between theology and science -which disturbed so many eminent though timid minds, including not a few men of science, a quarter of a century ago, has now been transferred almost wholly to the field of the theological contestants; and science may safely leave them to determine the issue, since it is evidently coming by means of scientific methods. The grave fears entertained a few decades ago by distinguished theologians and publicists as to the stability of the social fabric under the stress put upon it by the rising tide of scientific ideas have not been realised. And, on the other hand, the grave doubts entertained by distinguished men of science a few decades ago as to the permeability and ready response of modern society to that influx of new ideas have likewise not been realised. It is true that we sometimes read of theological tests being applied to teachers of biology, and hear, occasionally, of an earnest search for a good Methodist or a good Presbyterian mathematician; but such cases may be left for settlement out of court by means of the arbitration of our sense of humour.

It seems not unlikely, also, that there may persist, for a long time to come, a more or less guerilla "warfare of science" with our friends the dogmatists and the humanists. Some consider this conflict to be, in the nature of things, irrepressible. But I think we may hope, if we may not confidently expect, that the collisions of the future will occur more manifestly than they have in the past in accordance with the law of the conservation of energy; so that the heat evolved may reappear as potential energy in the warmth of a kindly reasonableness on both sides, rather than suffer degradation to the level of cosmic frigidity.

Great questions, also, of education, of economic, industrial and social conditions, and of legal and political relations are now demanding all the light which science can bring to bear upon them. Though tardily perceived, it is now admitted, generally, that science must not only participate in the development of these questions but that it alone can point the way to the solutions of many of them. But there is no halting ground here. Science must likewise enter and explore the domain of manners and morals ; and these, though already largely modified unconsciously, must now be modified consciously to a still greater extent by the advance of science. Only within quite recent times have we come to realise an approximation to the real meaning of the trite saying that the true study of man is man. So long as the most favoured individuals of his race, accordance with the hypothesis of the first centuries, looked upon him as a fallen, if not a doomed, resident of an abandoned reservation, there could be roused little enthusiasm with respect to his present condition; all thought was concentrated on his future prospects. How incomparably different does he appear to the anthropologist and to the psychologist at the beginning of the twentieth century! In the light of evolution he is seen to be a part of, and not apart from, the rest of the universe. The transcendent interest of this later view of man lies in the fact that he can not only investigate the other parts of the universe, but that he can, by means of the same methods, investigate himself.

I would be the last to look upon science as furnishing a speedy or a complete panacea for the sins and sorrows of mankind; the destiny of our race is entangled in a cosmic process whose working is thus far only dimly outlined to us; but it is nevertheless clear that there are available to us immense opportunities for the betterment of man's estate. For example, to mention only one of the lines along which improvement is plainly practicable, what is to hinder an indefinite mitigation, if not a definite extinction, of the ravages of such dread diseases as consumption and typhoid fever? Or what, we may ask, is to hinder the application to New York, Philadelphia and Chicago of as effective health regulations as those now applied to Havana? Nothing, apparently, except vested interests and general apathy. We read, not many years ago, that a city of about one million inhabitants had, during one year, more than six thousand cases of typhoid fever. The cost to the city of a single case may be estimated as not less, on the average, than one thousand dollars, making an aggregate cost to that city, for one year, of more than six millions of dollars. Such a waste of financial resources ought to appeal to vested interests and general apathy even if they cannot be moved by any higher motives. Thanks to the penetration of the enlightenment of our times, distinct advances have already been made in the line of effective domestic and public sanitation; but the good work accomplished is infinitesimal in comparison with that which can be, and ought to be, done. It is along this, and along allied lines of social and industrial economy, that we should look, I think, for the alleviation of the miseries of mankind. No amount of contemplation of the beatitudes, human or divine, will prevent men from drinking contaminated water or milk; and no fear of future punishments, which may be in the meantime atoned for, will much deter men from wasting their substance in riotous living. The moral certainty of speedy and inexorable earthly annihilation is alone adequate to bring man into conformity with the cosmic rules and regulations of the drama of life.

And, finally, we must reckon amongst the most important of the conditions favourable to the progress of science the unexampled activity in our times of the scientific spirit as manifested in the work of all kinds of organisations from the semireligious Chautauquan assemblies up to those technical societies whose programmes are Greek to all the world beside. Literature, linguistics, history, economics, law and theology are now permeated by the scientific spirit, if not animated by the scientific method. Curiously enough, also, the terminology, the figures of speech and the points of view of science are now quite common in realms of thought hitherto held somewhat scornfully above the plane of materialistic phenomena. Tyndall's Belfast address, which, twenty-seven years ago, was generally anathematised, is now quoted with approval by some of the successors of those who bitterly denounced him and all his kind. Thus the mere lapse of time is working great changes and smoothing out grave differences of opinion in favour of the progress of science in all the neighbouring provinces with which we have been able hitherto to maintain only rather strained diplomatic relations.

Still more immediately important to us are the evidences of progress manifested in recent years by this Association and by its affiliated societies. Our parent organisation, though half a century old, is still young as regards the extent in time of the functions it has undertaken to perform. It has accomplished a great work; but in the vigour and enthusiasm of its youth a far greater work is easily attainable. Exactly how these functions are to be developed no man can foresee. We may learn, however, in this, as in other lines of research, by methods with

NO. I664, VOL. 64] 
which we are well acquainted, namely, by the methods of care fully planned and patiently executed observation and experiment. The field for energetic and painstaking effort is wider and more attractive than ever before. Science is now truly cosmopolitan; it can be limited by no close corporations, and no domain of scientific investigation can be advantageously fenced off, either in time or in place, from the rest. While every active worker of this or of any affiliated society is, in a sense, a specialist, there are occasions when he should unite with his colleagues for the promotion of science as a whole. The results of the specialists need to be popularised and to be disseminated among the people at large. The advance of knowledge to be effective with the masses of our race must be sustained on its merits by a popular verdict. To bring the diverse scientific activities of the American continent into harmony for common needs; to secure cooperation for common purposes; and to disseminate the results of scientific investigation among our fellow men, are not less, but rather much more, than in the past the privilege and the duty of the American Association for the Advancement of Science.

Viewed, then, in its broader aspects, the progress of science is involved in the general progress of our race; and those who are interested in promoting the former should be equally earnest in securing the latter. However much we may be absorbed in the details of our specialities, when we stop to think of science in its entirety, we are led, in the last analysis, back to the problem of problems-the meaning of the universe. All men "gifted with the sad endowment of a contemplative mind" must recur again and again to this riddle of the centuries. We are, so to speak, whatever our prepossessions, all sailing in the same boat on an unknown sea for a destination at best not fully determined. Some there are who have, or think they have, the Pole Star always in sight. Others, though less confident of their bearings, are willing to assume nothing short of second place in the conduct of the ship. Others, still less confident of their bearings, are disposed to depend chiefly on their knowledge of the conpass and on their skill in dead reckoning. We of the latter class may not impugn the motives or doubt the sincerity of the first two classes. We would find it difficult, probably, to dispense with their company in so long a journey after becoming so well acquainted with them; for among them we may each recall not a few of those rarer individuals of the genus homo called angels on earth. But it must be said in all truth, to resume the figure, that they have neither improved much the means of transportation nor perfected much the art of navigation. They have been sufficiently occupied, perhaps, in allaying the fears of the timid and in restraining the follies of the mutinous. Other types of mind and other modes of thought than theirs have been essential to work out the improvements which separate the earlier from the later nautical equipments of men; such improvements, for example, as mark the distinction between the dug-out of our lately acknowledged relatives, the Moros and the Tagalogs, from the Atlantic-liner of to-day. At any rate, we are confronted by the fact that man's conceptions of the universe have undergone slow but certain enlargement. His early anthropocentric and anthropomorphic views have been replaced, in so far as he has attained measurable advancement, by views that will bear tests of astronomy and anthropology. He has learned, slowly and painfully, after repeated failures and many steps backward, to distinguish, in some regions of thought, the real and the permanent from the fanciful and fleeting phenomena of which he forms a part. His pursuit of knowledge, in so far as it has led him to certainty, has been chiefly a discipline of disillusionment. He has arrived at the truth not so much by the genius of direct discovery as by the laborious process of the elimination of error. Hence he who has learned wisdom from experience must look out on the problem of the universe at the beginning of the twentieth century with far less confidence in his ability to speedily solve it, and with far less exaggerated notions of his own importance in the grand aggregate of Nature, than man entertained at the beginning of our era. But no devotee of science finds humiliation in this departure from the primitive concepts of humanity. On the contrary, he has learned that this apparent humiliation is the real source of enlightenment and encouragement; for notwithstanding the relative minuteness of the speck of cosmic dust on which we reside, and notwithstanding the relative incompetency of the mind to discover our exact relations to the rest of the universe, it has yet been possible to measure that minuteness and to determine that incompetency.
These, in brief, are the elements of positive knowledge at which we have arrived through the long course of unconscious, or only half-conscious, experience of mankind. All lines of investigation converge towards or diverge from these elements. It is along such lines that progress has been attained in the past, and it is along the same lines that we may expect progress to proceed in the future.

\section{THE GLASGOW MEETING OF THE BRITISH ASSOCIATION}

THE seventy-first annual meeting of the British Association came to an end yesterday. For the purposes of the meeting the entire accommodation of the College Buildings was placed at the disposal of the Association by the University authorities, while for the opening meeting the St. Andrew's Hall was granted by the Corporation. Between 2000 and 3000 persons attended at the St. Andrew's Hall to hear the opening address of the president, Prof. A. W. Rücker, F.R.S. The retiring president, Sir William Turner, F.R.S., took the chair and introduced his successor, who afterwards delivered the presidential address, which was printed in last week's NATURE; and on Thursday morning the work of the sections commenced. Reports of the proceedings of the sections will appear in these columns as in previous years.

Melancholy interest was given to the meeting by the expressions of sympathy sent to the United States by the Association in connection with the assassination of the late President $M^{6}$ Kinley. At the first meeting of the General Committee, it was decided, upon the proposition of Sir Michael Foster, seconded by Sir John Evans, that the following telegram be sent on behalf of the Association :- "That the British Association for the Advancement of Science, assembled at Glasgow, desires to make known to President M'Kinley its feeling of horror at the attempt upon his life, its sympathy with him in his suffering, and its earnest hope for his speedy and complete restoration to health." A reply expressing thanks for the sympathy was received from the late President's: secretary on Thursday evening.

The news of the death of President $M^{\prime}$ Kinley became known on Saturday morning, when only two sections of the Association were sitting. At the close of the meeting of one of these sections-Educational Science-Sir John Gorst, the president, referred in touching terms to the profound grief which British people share with those of the United States at the terrible event that had occurred. The members present stood while expression was being given to their feelings by the president, and the following resolution, moved by him and seconded by Sir Philip Magnus, was adopted in solemn silence :-

"That this section of the British Association has heard with profound grief of the death of President M'Kinley, and records its deep sympathy with the family of the late President and the people of the United States of America in their domestic and national bereavement."

Many distinguished members of the Association were present at the opening by Lord Lister, on September I2, of the new Anatomical Department of Glasgow University, comprising an extensive laboratory, museum, \&c. The building has been presented to the University by the trustees of the late Mr. J. B. Thomson, and Lord Lister, in opening this important addition to the resources of the University, remarked that it comprised "as fine a laboratory as existed in the world, and at the same time a capacious, commodious, and beautiful anatomical museum adjoining it." Prof. Cleland has presented to the University his large collection of anatomical specimens, and this, with the specimens collected by his predecessors and placed in the museum, makes the 